\title{
La sedación: una herramienta indispensable para muchos procedimientos
}

Dr. Mohammad Hasan Abed-Raduan

' Especialista en Anestesiología.

ISSN 0001-6002/2004/46/2/54 Acta Médica Costarricense,(C2004 Colegio de Médicos y Cirujanos
El progreso en los métodos de diagnóstico, y el uso masivo de estos, para los cuales la sedación volvió ser una herramienta indispensable, nos obliga a publicar temas relacionados con el fin de mejorar, el conocimiento en este ámbito, y tener guías claras para su implementación, especialmente por que se usan fuera de sala de operaciones, donde las condiciones no siempre son las idóneas y, por consiguiente, las complicaciones son más frecuentes.

Hay un convencimiento creciente de que se requieren especialistas para desempeñar este rol, con capacidad para prevenir y detectar posibles complicaciones con medidas rápidas y eficaces.

Las mínimas condiciones que deben existir son las correlacionadas con la seguridad del paciente, para que se garantice la adecuada ventilación y el desempeño cardiovascular. Debe de tenerse en cuenta un acceso fácil y seguro para el control de la vía aérea, pues muchas veces hay competencia por este, entre el anestesiólogo y el especialista operador como en el caso de gastroenteroscopías, broncoscopías, etc.

El exceso de confianza de algunos pocos colegas, en ocasiones ha conducido a complicaciones irreversibles, que podrían haber sido evitadas, o enmarcadas dentro del riesgo aceptable, por lo que es preciso partir del estado físico y la valoración previa al procedimiento hecha por una persona calificada. En el editorial del volumen 44: No 3, julio - setiembre 2002, se refirió al tema de la categorización de los pacientes, y también en el artículo del Dr. Gerardo Jiménez Trejos, la técnica de la triple sinergia para la sedación.

La revisión incluida en este número tiene el mérito de especificar las condiciones mínimas para proceder con una sedación fuera de las salas de operaciones, y resume los fármacos más usados en las sedaciones, con el propósito de hacerlos más accesibles para todo el cuerpo médico nacional.

Esperamos que cada día estemos más apegados a tales guías y que nunca tengamos complicaciones por su falta del uso.

Los problemas para una implementación completa de estas guías pueden obedecer a varios factores, entre ellos, la existencia de grupos que:

1. Del todo no se han enterado de estas condiciones.

2. No las practican porque suben los costos de los procedimientos.

3. Se resisten al cambio.

4. Las rechazan por no formar parte de una comisión que implementará guías en el ámbito nacional.

De cualquier manera, no existe justificación frente a una problemática tan seria, que puede causar el deceso de un paciente. 